\title{
Article \\ Titanium metallization coating deposited on AlN ceramics substrate by means of friction surfacing process
}

\author{
Michał Hudycz ${ }^{1 *}$ \\ 1 Warsaw University of Technology, Poland \\ * Correspondence: m.hudycz@wip.pw.edu.pl
}

Received: 04.01.2020; Accepted: 18.03.2020

\begin{abstract}
The article characterizes a titanium metallization coating frictionally deposited on the surface of AlN ceramics. The method of preparing materials for metallization and the idea of the process were described. The results of stereometric tests of coating surfaces, metallographic tests and phase analysis are presented. Tests were carried out on the adhesion of the coating to the substrate and brazing tests of metallized ceramics with an FeNi42 alloy in an argon sheath using AgCu28 eutectic solder.
\end{abstract}

Keywords: friction surfacing; metallization; ceramics-metal joints

\section{Introduction}

The growing share of modern ceramic materials in industrial products and other utility structures is permanently associated with the need to combine them with metals. The specific properties of advanced ceramics are often used locally in the structure, in other product/structure areas, under the influence of loads dangerous for ceramics, they may be undesirable. For this reason, ceramic-metal joints are used. Where possible, technologically simple methods of joining are used, such as gluing and form-joining of ceramic fragments of a structure, but in most cases a joint with a strength comparable to that of the joined components, resistant to thermal loads and additionally airtight is required. Metal-ceramic (M/C) joints allow the association of different properties into a specific product feature. Ceramics with metals are combined in two ways, directly [1,2], where the configuration of material pairs is very limited [3,4], indirectly by soldering

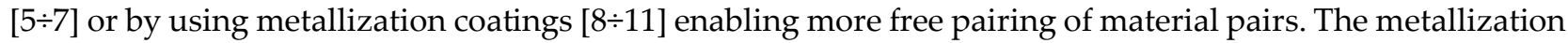
of ceramic surfaces is a necessary intermediate step in the joining of solid metal and ceramic materials. The metallization coating is also a kind of metal-ceramic joint, its purpose is to change the surface properties of ceramics so as to enable wetting with liquid metal (inactive in relation to the non-metallic surface) in the next technological stage [12]. Metallization technologies used until today in industry and developed in the middle of the last century were based on sintering of metallic pastes applied by screen printing on ceramic surfaces [13], a long-term, multi-stage and energy-consuming process, however, enabling obtaining the highest quality joint. However, the cost of making such coatings is relatively high, the process is complicated and multi-stage. It is necessary to use protective atmospheres with moist hydrogen or high vacuum, in addition, high temperature and long duration of the process are used. In industrial applications the most common methods used are: powder metallization, active soldering, diffusion welding, coating deposition methods using PVD (Physically Vapor Deposition) [8], CVD (Chemically Vapor Deposition) and IPD (Impulse Plasma Deposition) [14:16], as well as modification of the ceramic surface through high-energy implantation of metal ions [17].

Metallization of the surface of ceramic materials is the basic, essential stage in the production of ceramicmetal joints, enabling wider configuration of pairs of joined materials than when welding without a metallization coating. A properly designed metallization coating can additionally constitute a joint element to compensate for stress and reduce the importance of extremely different properties of ceramic combined with metal materials $[18,19]$. The article presents the conditions of friction metallization of AlN ceramics with titanium and selected properties of such a deposited metallization coating.

\section{Materials and methods}

The choice of titanium as the (coating) material for metallization was influenced by the conclusions of the literature analysis regarding the relatively high chemical affinity for both $\mathrm{Al}$ and $\mathrm{N}$ ceramic components, but also the role it plays in the formation of ceramic-metal joints. Titanium is an active solder component that 
facilitates the wettability of ceramic surfaces. The high chemical affinity of titanium for nitrogen and aluminum can lead to the formation of chemical compounds from Ti-Al and Ti-N systems. Titanium nitrides are particularly easily formed, and if the metallization takes place in an air atmosphere, titanium oxides may also be formed. Of titanium oxides, $\mathrm{TiO}$ is interesting, because of its wettability with liquid copper, it can be used to create target ceramic-metal joints made after the metallization process. Ti-Al compounds exhibit much greater metal wettability than ceramics. Thermodynamic considerations [20] indicate the possibility of creating $\mathrm{Ti}$ and $\mathrm{Al}$ chemical compounds after AlN reduction. The presented considerations significantly substantiate the formation of a bond at the interface between the titanium coating with a ceramic substrate based on atomic bonds. The coating material used was Grade 2 titanium with the chemical composition shown in table I.

Table I. Chemical composition of titanium Grade 2, wt.

\begin{tabular}{cccccc}
\hline Fe & $\mathbf{O}$ & $\mathbf{C}$ & $\mathbf{N}$ & $\mathbf{H}$ & $\mathbf{T i}$ \\
\hline \multirow{2}{*}{ Max. 0.25\% } & Max. 0.25\% & Max. 0.08\% & Max. 0.03\% & $\begin{array}{c}\text { Max. } \\
0.015 \%\end{array}$ & base \\
\hline
\end{tabular}

AlN nitride ceramics with a purity of $99 \%$ produced by sintering powders at the Institute of Electronic Materials Technology in Warsaw was used in the research. The base material was in the form of disks with dimensions of $\varnothing 68 \mathrm{~mm}$, thickness $5 \mathrm{~mm}$. The faces of the discs were intended for metallization.

In the raw state after sintering, the ceramic discs were not flat, the average value of the curvature arrow on the face of the disc was $0.5 \mathrm{~mm}$. Due to the fact that during metallization it was anticipated to use relatively high (as for ceramics) values of the axial pressure of the friction tool (about $14 \mathrm{MPa}$ ), the flatness of the metallized surface and its parallelism to the support surface by mechanical treatment were ensured. Ceramic discs were glued with high-strength Loctite EA 3430 resin into sockets in metal holders made of $10 \mathrm{~mm}$ thick steel sheet. The ceramic framed with a metal handle was ground with a diamond grinding wheel, obtaining the flatness of the upper surface and its parallelism to the base of the frame (Fig. 1a). Figure $1 \mathrm{~b}$ shows the XRD pattern of the metallized ceramics.

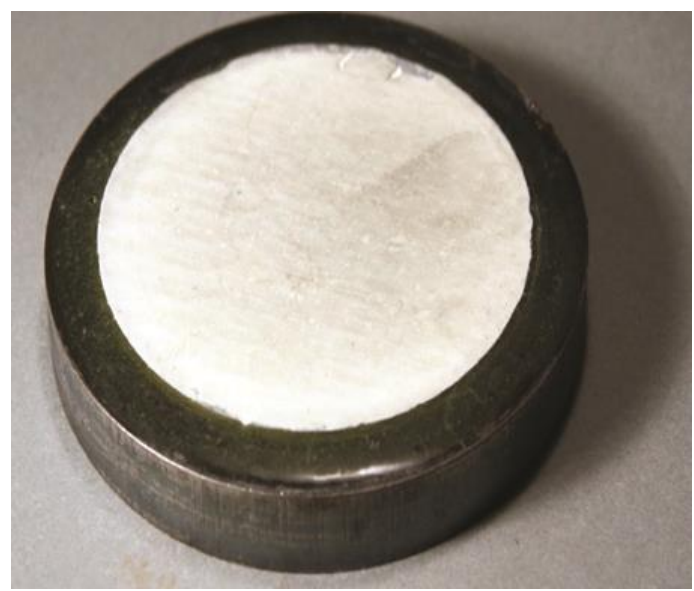

(a)

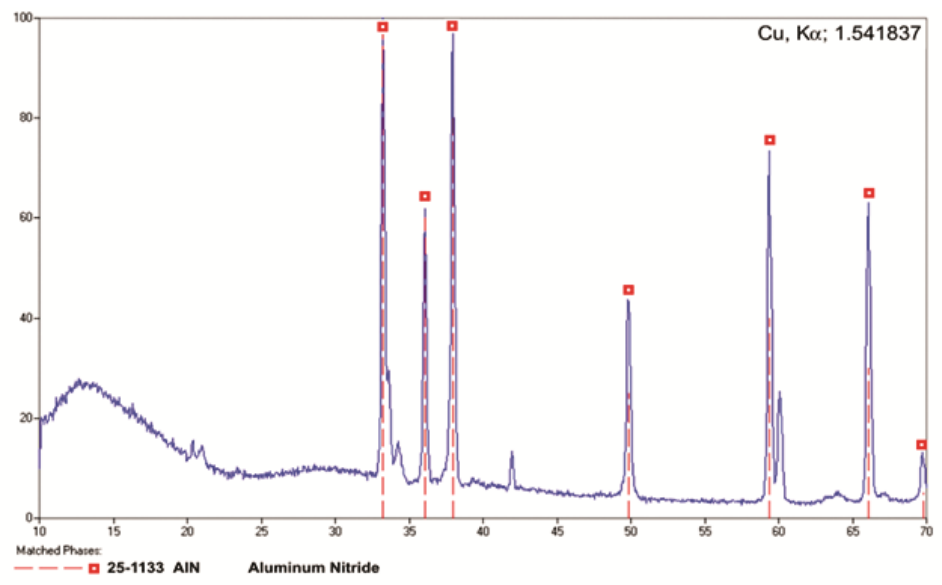

(b)

Fig. 1. AlN ceramic substrate, a) prepared for friction metallization, mounted in a steel handle, after grinding the face, b) XRD pattern of AlN ceramics used in tests

The concept of metal coating deposition on ceramics used in the work is derived from the observation of friction welding of ceramics with metals. The use of friction welding method for joining metal and ceramic elements is a relatively new issue [21]. In 2003, one of the first experimental works in Poland [4,22] combining $\mathrm{Al}_{2} \mathrm{O}_{3}$ oxide ceramics with metals was carried out at the Warsaw University of Technology, in the Welding Engineering Department. As a result of this work, high-quality $\mathrm{Al}_{2} \mathrm{O}_{3}-\mathrm{Al}_{\text {and }} \mathrm{Al}_{2} \mathrm{O}_{3}-\mathrm{Cu}$ connections were obtained. In 2012, the process of friction metallization of $\mathrm{Al}_{2} \mathrm{O}_{3}$ ceramics with titanium was described as part of the work of the Welding Engineering Department team at the Warsaw University of Technology [12,23].

This work uses a new concept based on a rotary tool whose face is rubbed onto the surface of ceramics, as shown in figure $2 b$. 


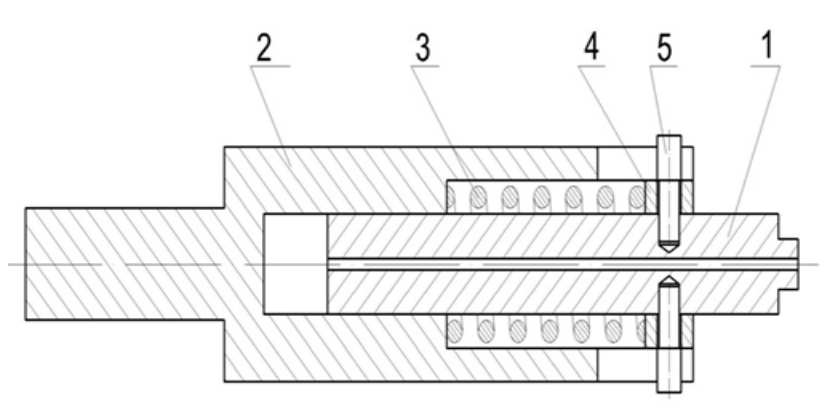

(a)

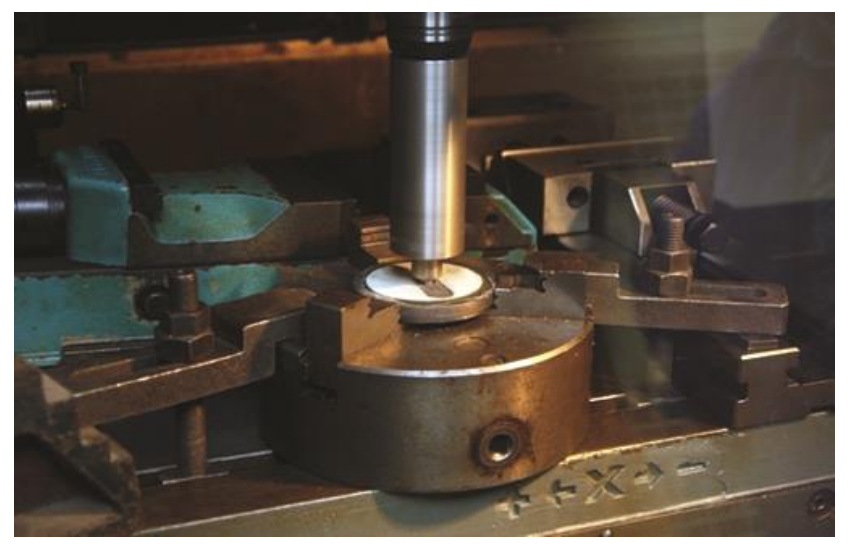

(b)

Fig. 2. a) Diagram of the friction tool, b) metallization process

Numerous technological tests were carried out to determine the best process parameters. The effects of metallization were assessed according to several criteria: continuity, uniformity and thickness of the deposited coating. The following process parameters were determined: rotational speed of the metallizing tool $4000 \mathrm{rpm} ; 2.9 \mathrm{MPa}$ pressure on the tool face, $40 \mathrm{~mm} / \mathrm{min}$ feed, the process was carried out in an argon protective atmosphere and optionally without gas protection. When producing wide multi-stitch coatings, the adjacent stitches overlapped with $5 \%$ of the stitch width. Two variants of coatings were produced, consisting of straight stitches (Fig. 3a) and guiding the tool along a programmed spiral (Fig. 3b).

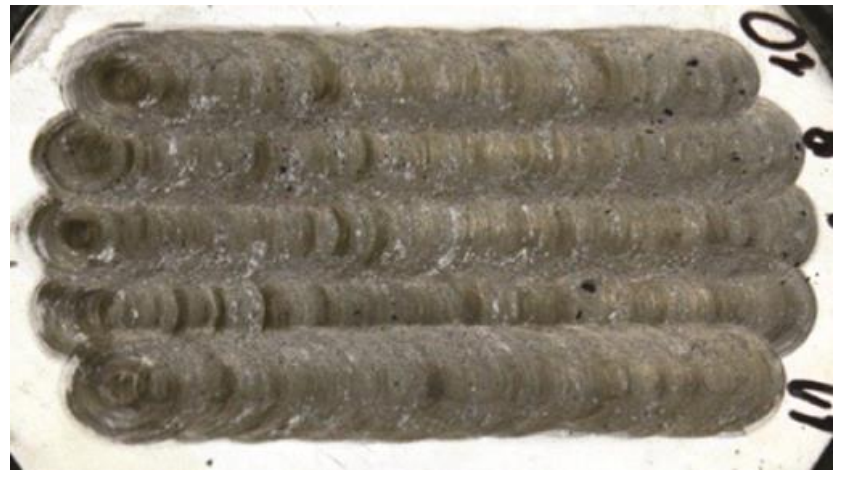

(a)

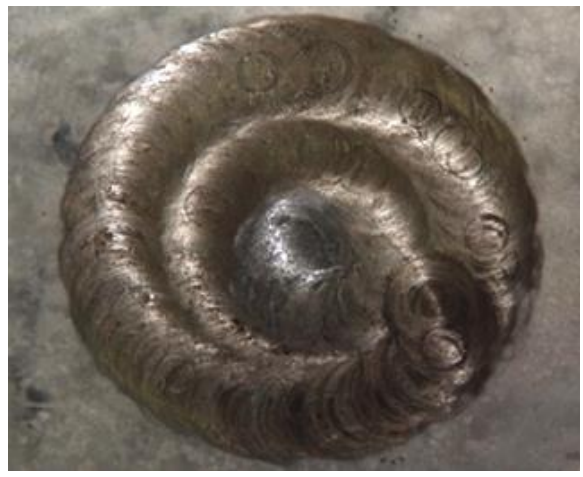

(b)

Fig. 3. Images of metallization coatings on an AlN substrate a) straight stitches, b) spiral stitch

The coatings were subjected to structural micro and macroscopic tests, adhesion tests and phase analysis. Samples for tests were taken by cutting out strands of individual coatings using a $0.6 \mathrm{~mm}$ thick diamond circular saw. The cut was made with intensive liquid cooling, guiding the saw along the side edges of the stitches at a depth of $5 \mathrm{~mm}$ from the metallized surface, through the binding and ceramics. Then similar cuts were made perpendicularly at a distance of $10 \mathrm{~mm}$. A metallized substrate with such a grid of cuts was laid on a heating plate with a stabilized temperature of $120^{\circ} \mathrm{C}$ in order to disintegrate the EA3430 resin.

\section{Selected properties of the metallization coating - own research Surface morphology and stereometric structure of the metallization coating}

A view of the surface of the Ti coating frictionally deposited on AlN is shown in figure 4a. SEM observations were performed on a JEOL microscope, USA. The surface of the coating is characterized by a clear directionality resulting from the directional friction and geometry of the friction tool. Figure $4 \mathrm{~b}$ shows the surface image (recorded on an Olympus stereoscope) of a multi-stitch rectangular coating, with the stitch width measurement on a microscope at the last contact of the friction tool with the ground. 


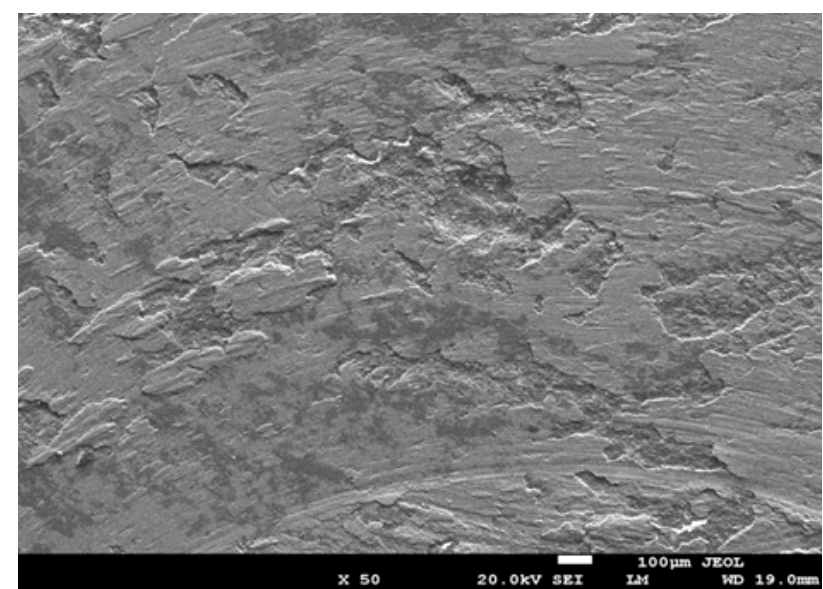

(a)

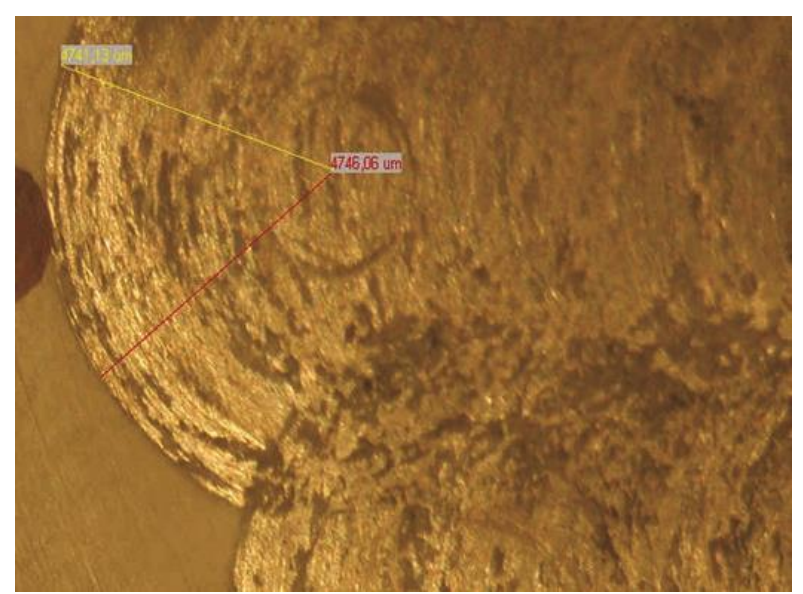

(b)

Fig. 4. Surface of the metallization coating: a) SEM image of the surface of the Ti coating, b) image from a stereoscopic microscope, multi-stitched Ti coating deposited frictionally on an AlN substrate, the stitch radius is marked, a visible image of the overlap of parallel coating stitches

No cracks or open pores were recorded on the surface. The coating has a thickness in the range of $2 \div 6 \mu \mathrm{m}$.

From the point of view of the purpose of the coating as a transition layer in processes such as soldering metallized ceramics with metals, an important feature in addition to wettability with solders is the stereometric structure of the surface having a significant effect on solderability. Surface geometry measurements were performed on a nanofocus optical scanning profilometer $\mu$ scan select. Parameters of the measurement: measurement field (X direction) $5 \mathrm{~mm} \times$ ( $Y$ direction) $4.5 \mathrm{~mm}$. The roughness parameters of a randomly selected surface after filtration - Gauss $0.08 \mathrm{~mm}$ were determined and a stereometric map of the tested surfaces was presented, shown in figure 5. The surface structure of the tested mechanically applied coatings is anisotropic, shows a clear direction of hills and pits, which is a representation of the rotational movement of the tool with simultaneous feed. Figure 6 presents graphs showing a cloud of registered roughness profiles in the $X$ and $Y$ directions. Individual profiles for both directions obtained in the center of the tested field as well as the average $\mathrm{Ra}$ and $\mathrm{Rz}$ values for all measurements in both directions are also shown. The stereoscopic structure of the top layer of the metallization coating is anisotropic and has a relatively low roughness, average $\mathrm{Ra}=0.404 \mu \mathrm{m}$ in the $\mathrm{y}$ direction and $0.9 \mu \mathrm{m}$ in the $\mathrm{x}$ direction. $\mathrm{Rz}$, $1.96 \mu \mathrm{m}$ and $6.72 \mu \mathrm{m}$, respectively. This condition promotes wettability with liquid metal solders due to the stereometric structure of the surface characteristic of the phenomenon of capillary attraction, stimulating wettability.

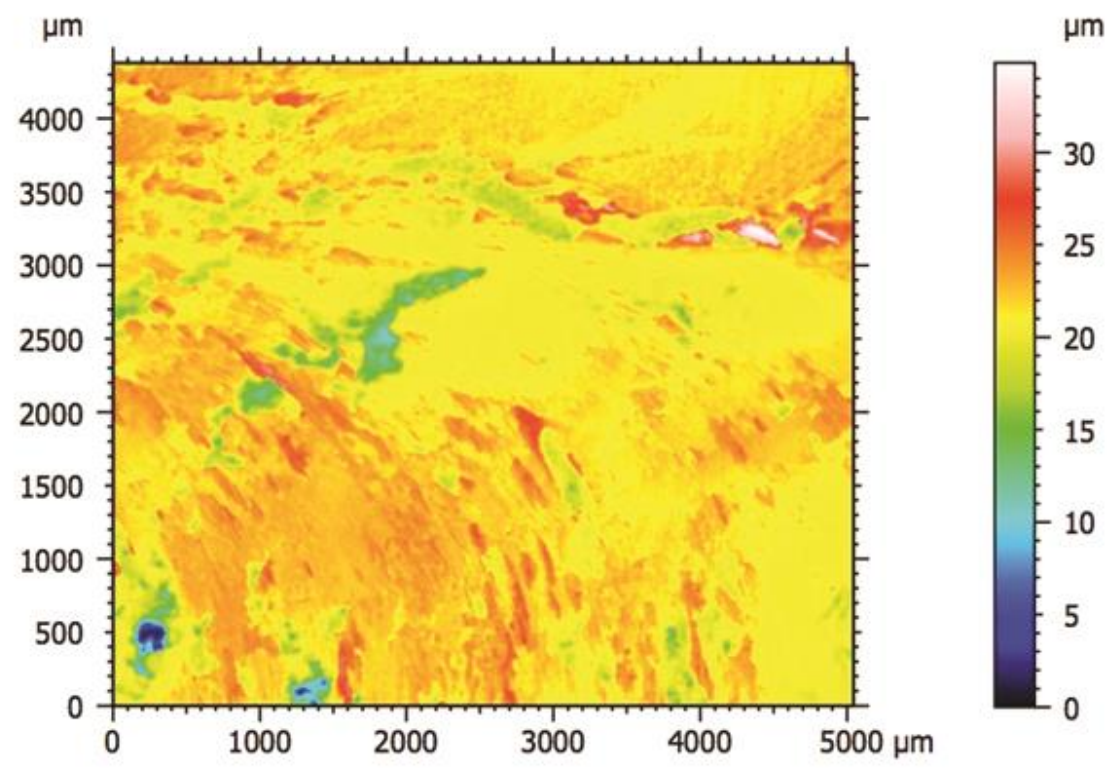

Fig. 5. A stereometric map of the surface of the metallization coating 


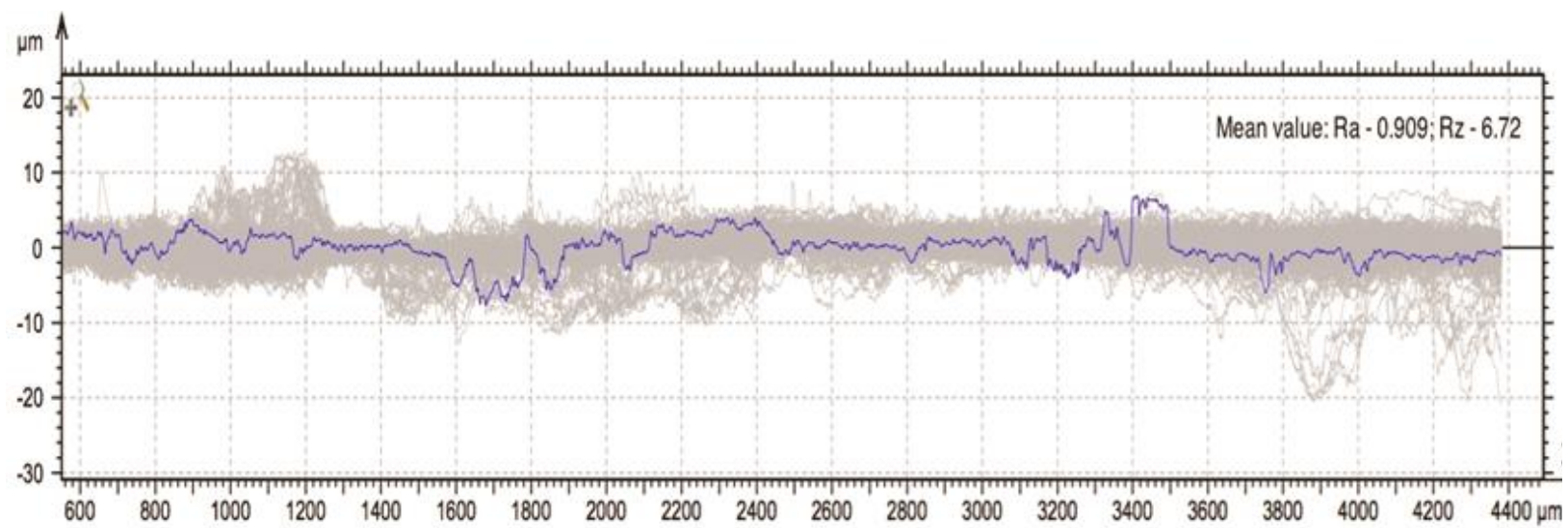

(a)

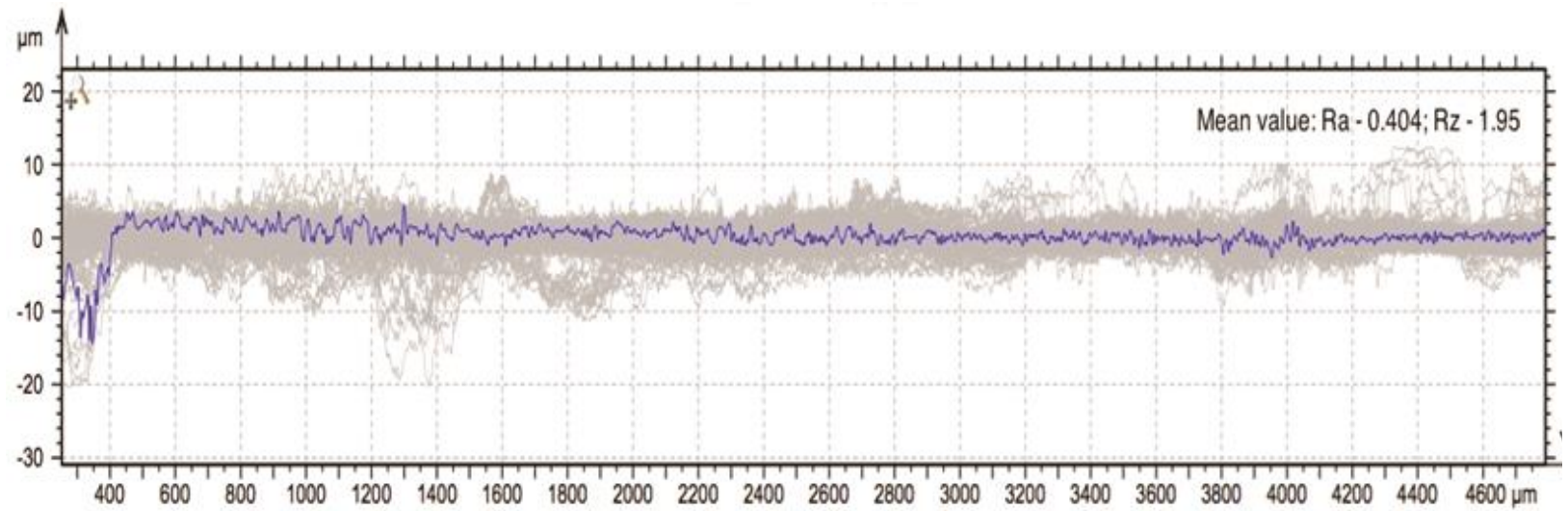

(b)

Fig. 6. Set of roughness profiles of the metallization coating in the directions: a) $-y, b)-x$

\section{The microstructural structure of the metallization coating}

Figure 7a shows the SEM image (BSE detector, JEOL microscope, USA) of the outer surface of the coating at its border with the substrate. In all types of coatings, the coverage border zone is a sensitive area with a high risk of delamination. Due to the relatively high level of internal stresses resulting from, among others, the technological conditions of coating application and extremely different physical properties of ceramics and metal, such as thermal conductivity and coefficient of thermal expansion. In the described case, no tendency of coating delamination was observed. The boundary line of the coating is developed, but without cracks and discontinuities. Figure $7 \mathrm{~b}$ shows the microstructure of the coating obtained on an oblique specimen $\left(\sim 12^{\circ}\right.$ to the coating surface). Figure 8 presents the picture of the structure of the AlN connection with the frictionally deposited Ti coating with linear distribution of elements ( $\mathrm{Ti}, \mathrm{Al}, \mathrm{N}$ and $\mathrm{O}$ ).

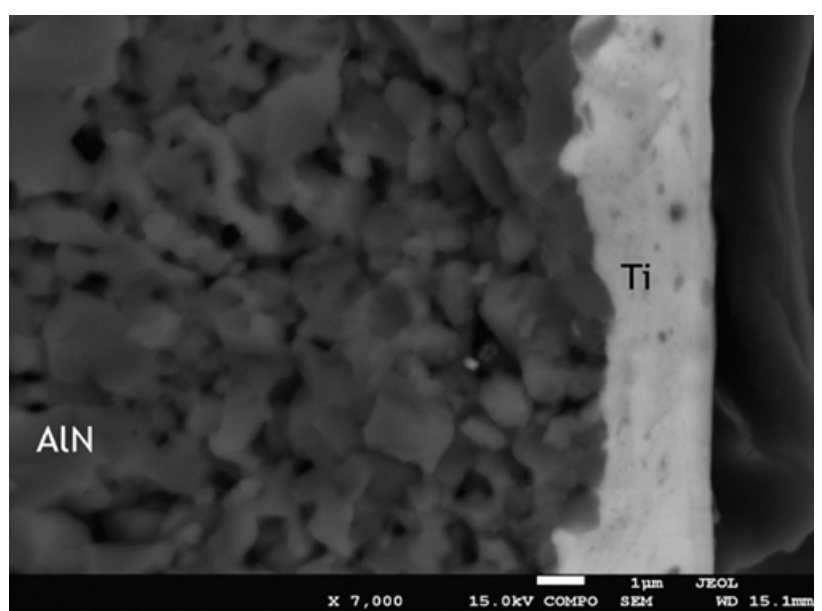

(a)

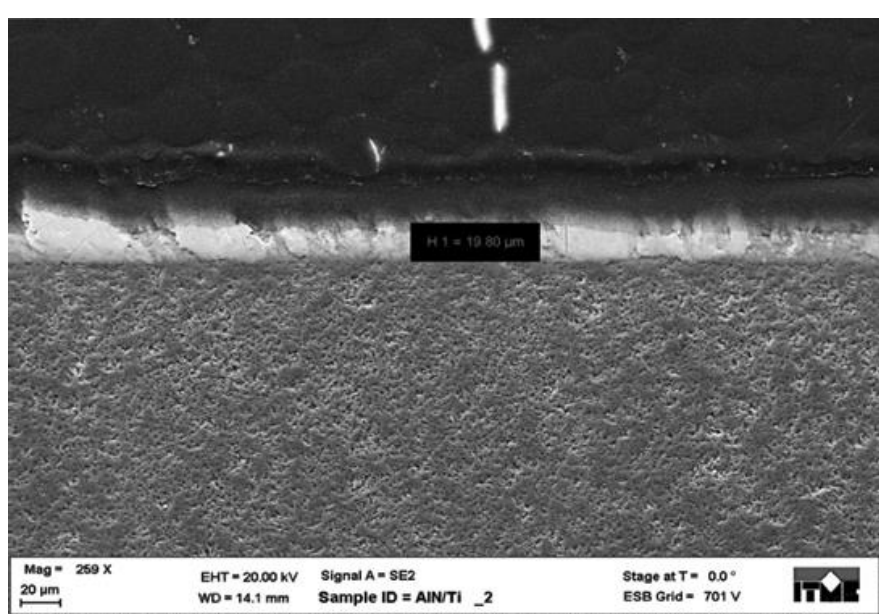

(b)

Fig. 7. Deposited coating microstructure: a) SEM image of the cross-section of the AlN-Ti coating, b) diagonal cut at an angle of $\sim 12^{\circ}$ to the surface of the titanium coating 
The AlN-Ti interface was examined with a scanning electron microscope in a cross-section perpendicular to the surface. The concentration curves of aluminum and titanium intersect the interfacial boundary area, indicating slight mutual penetration. On this basis, it cannot be said about a diffusion connection or the formation of a diffusion interlayer. The connection is mechanical-adhesive (combined), highly plasticized titanium effectively fills the unevenness of the developed ceramic top layer and surface porosity, mechanically binding the coating to the substrate. Figure 8 shows the result of a linear analysis of the elements, the scanning line passes through the grain of AlN ceramics in a titanium coating. At the inclusion site, $\mathrm{Al}$ and $\mathrm{N}$ concentration was recorded at the expense of Ti. Figure 9 shows the spectra of elements from the marked areas in the substrate and coating.

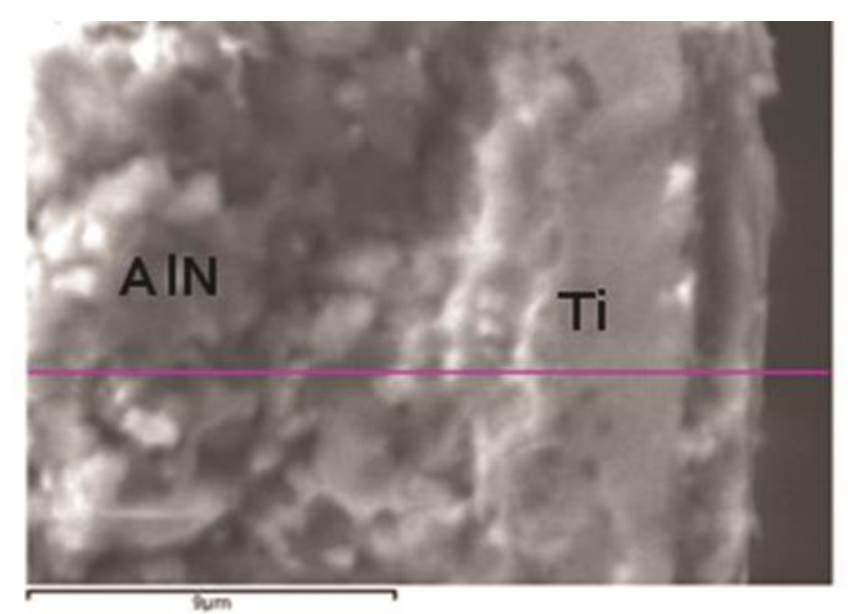

(a)

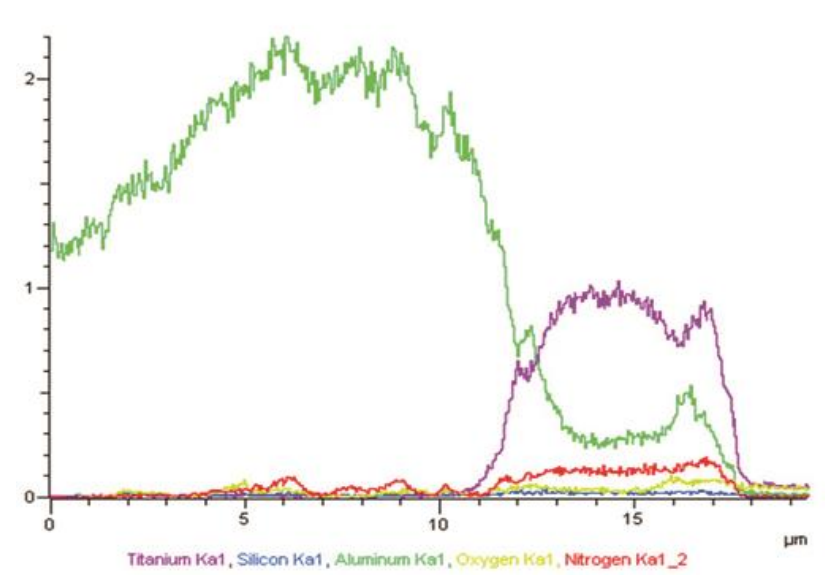

(b)

Fig. 8. Linear distribution of elements on the cross-sectional surface of the substrate-coating system by the inclusion of AlN in the coating

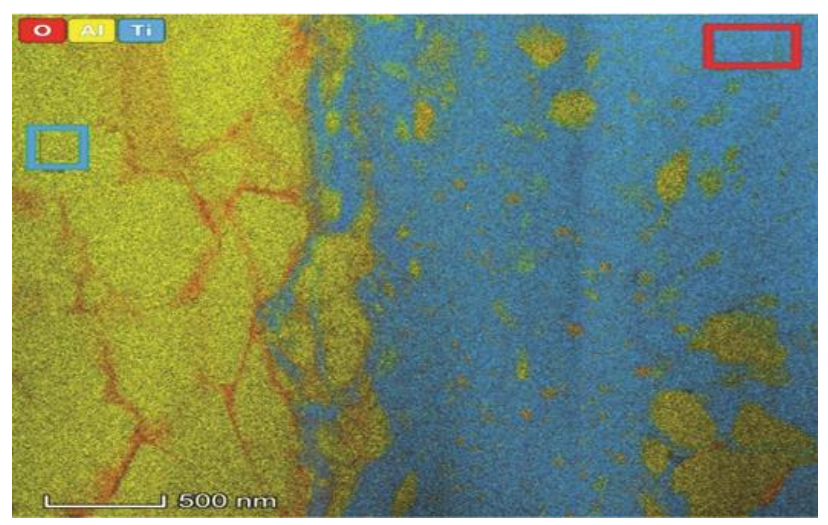

(a)

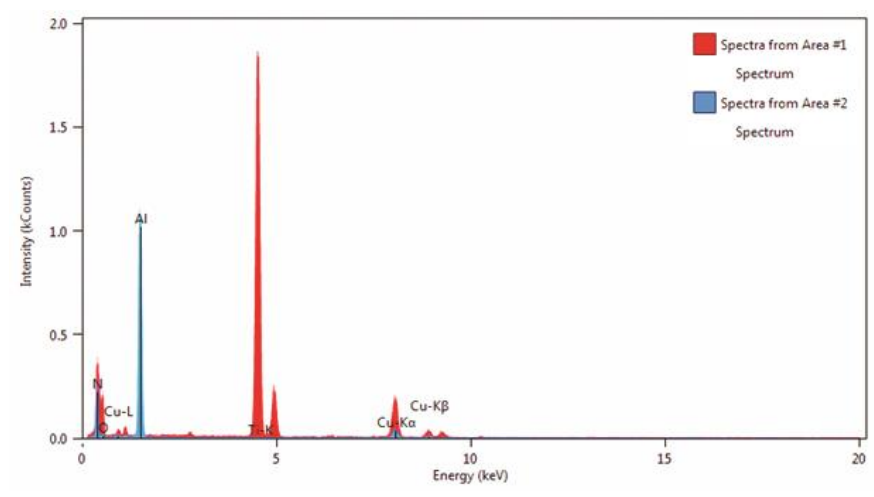

(b)

Fig. 9. a) Surface distribution of $\mathrm{O}, \mathrm{Al}$ and $\mathrm{Ti}$ in the substrate-coating border with selected areas of spectrum analysis, b) spectra of elements from selected areas in the substrate and coating

\section{Phase analysis of the frictionally deposited Ti coating}

The phase structure of the metallization coating is very important due to the required wettability and solderability of the surface. The technological problem of bonding to the titanium coating results from the difference in the form of relatively good wettability of pure titanium and worse wetting of titanium oxides and nitrides with most solders. The proper phase structure of the tested coating can significantly affect the solder flow and the process of soldering. Of the possible (from a thermodynamic point of view) to obtain phases in the structure of the friction coating, the Ti phase obtained under the conditions of argon protection during metallization is most advantageous. The phase analysis of the metallization coating made with argon protection indicates a relatively high homogeneity of the metallic structure of the matrix of the coating mainly consisting of pure titanium, practically amorphous (gives a very blurred diffraction signal) (Fig. 10). 


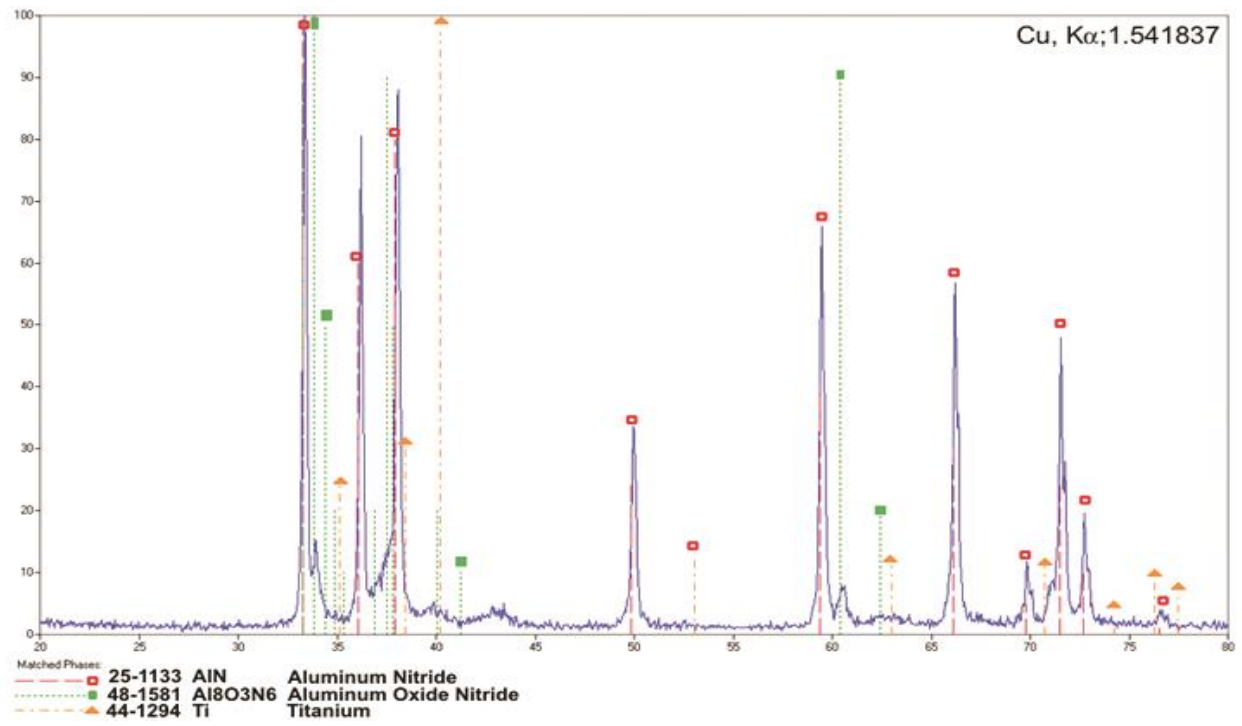

Fig. 10. XRD pattern of the Ti coating frictionally deposited on AlN ceramics

The diffraction pattern also has signals from the AlN crystal, this signal can come from both ceramic inclusions present in the coating, blurred from the ceramic substrate during metallization, as well as from the ceramic substrate, covered with a thin (just a few micrometers thick) titanium coating of the ceramic surface during the operation of the metallizing tool. No signal from the potential diffusion transition layer was recorded on any of the diffractograms. On XRD patterns, a signal from Al8O3N6 and Al5O6N are undesirable components of the ceramic substrate.

\section{Measurement of adhesion of the Ti metallization coating to the AlN substrate}

Assuming the adhesive nature of the coating's connection with the substrate, it was decided to use a device for assessing the adhesion of coatings with limited adhesion. The Elcometer 510 device was used for the measurements, which analyzes the detachment parameters from the surfaces of previously adhered mandrels with a diameter of $20 \mathrm{~mm}$. Large surfaces of frictionally deposited coatings with both rectangular and spiral surfaces were intended for the adhesion test. A highly adhesive, Araldite epoxy adhesive with a nominal tensile strength of up to $33 \mathrm{MPa}$ and a bonding time of $24 \mathrm{~h}$ was used. A single mandrel was glued for each subsequent coating as in figure 11. The results of the adhesion tests are summarized in table II.

Table II. Results of the frictionally deposited Ti coating adhesion test

\begin{tabular}{ccccccc}
\hline \multirow{2}{*}{ Ti coating } & \multicolumn{7}{c}{ Breaking stress [MPa] } \\
\cline { 2 - 7 } & Test I & Test II & Test III & Test IV & $\mathbf{x}$ & s \\
\hline Rectangular & 18.8 & 16.85 & 17.85 & 15.9 & 17.35 & 1.08 \\
Spiral & 14.3 & 5.88 & 9.6 & 8.88 & 9.66 & 3.02 \\
\hline
\end{tabular}

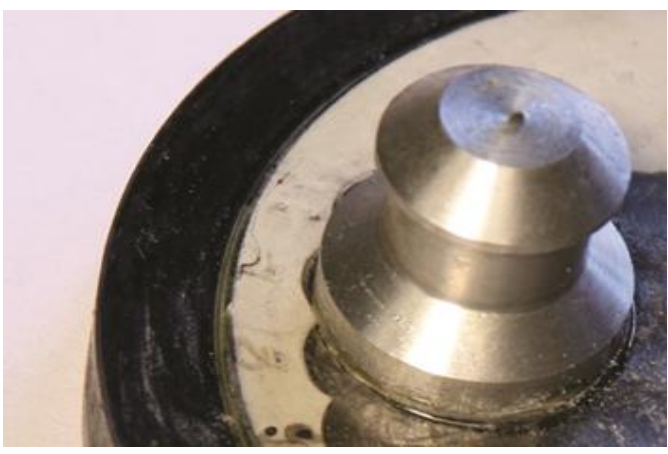

(a)

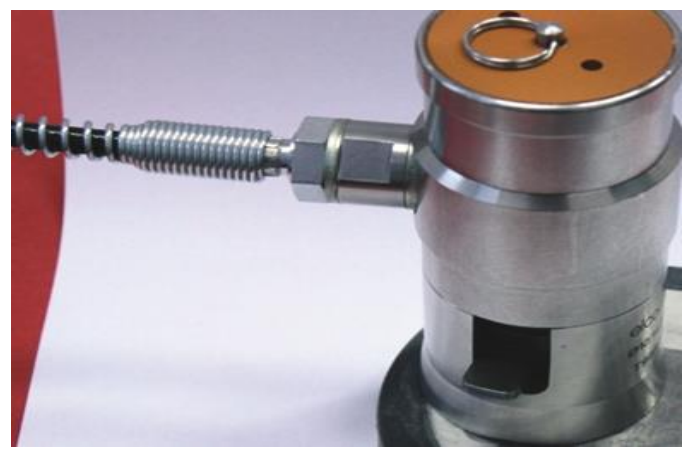

(b)

Fig. 11. a) Mandrel glued to the surface of the coating; b) the working head of the device fitted on the mandrel during the peel test

In all cases, the crack ran through the ceramic substrate, indicating that the coating's adhesion is higher than the tensile strength of the ceramic. This means that the combination of the Ti coating with the substrate, 
despite the fact that due to its nature it is not the strongest, it is not the connection but the mechanical properties of the ceramic substrate that limit the mechanical properties of the joint. It can be responsibly stated that in the context of the mechanical properties of the substrate, the adhesion of the frictionally deposited Ti coating is sufficiently high. It was observed that from the point of view of the bearing capacity of joints based on the frictionally deposited Ti coating, better properties were obtained for rectangular shaped coatings.

\section{The use of a metallization coating as an interlayer in a soldered joint}

One of the main purposes of producing a metallization coating on AlN ceramics is to obtain wettability with inactive solder, e.g. AgCu28, in a protective atmosphere of argon. The material obtained from metallization in argon shielding with the spiral coating shown in figure $3 \mathrm{~b}$ was chosen for soldering tests. Sampling was performed using an incision grid of approximate dimensions of $6 \times 6 \mathrm{~mm}$. The metal part joined in the soldering process is a disc made of FeNi42 alloy with a diameter of $12 \mathrm{~mm}$ and a thickness of $5 \mathrm{~mm}$. $10 \mathrm{AlN}$ metallized samples were prepared for soldering, half of them were nickel plated. The solder used in the process is an eutectic AgCu28 alloy in the form of foil with a thickness of $0.15 \mathrm{~mm}$. Soldering was carried out in a vacuum furnace chamber, which was pumped to the level of the pre-vacuum, then filled with argon through the metering valve, and after equalization of pressure the upper connector was opened and a constant argon flow of $14 \mathrm{l} / \mathrm{min}$ was maintained. The source of heat was an inductor with a graphite radiator. As a result of soldering processes, two types of joints were obtained, based on a friction metallization coating and with an additional nickel-plated metallization coating. Figure 12 shows soldered joints with a metallization coating, and figure 13 the microstructure of a soldered ceramic (AlN)-metal (FeNi42) joint.

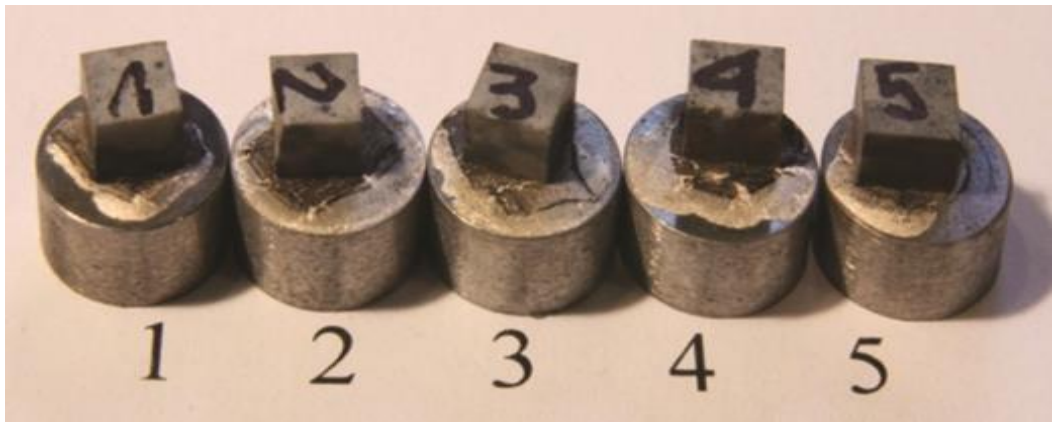

Fig. 12. Samples of AlN-AgCu28-FeNi42 soldered joints with Ti metallization

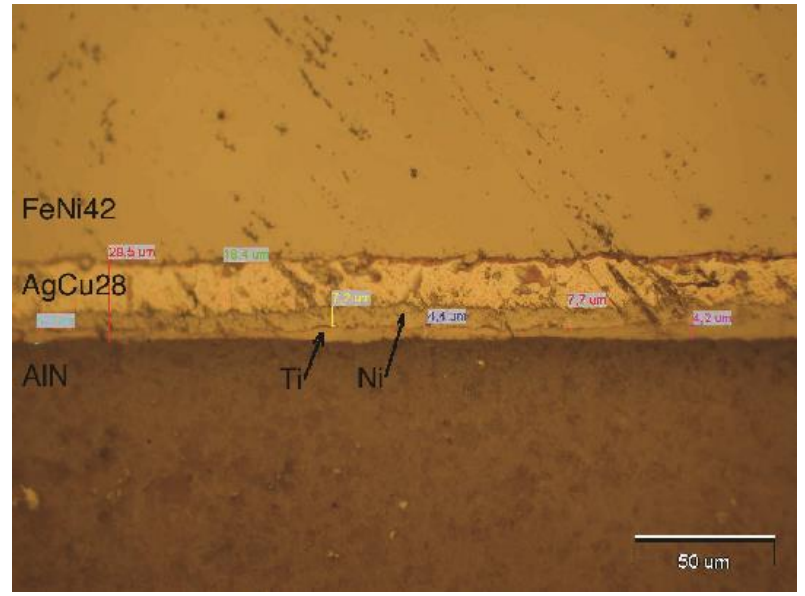

(a)

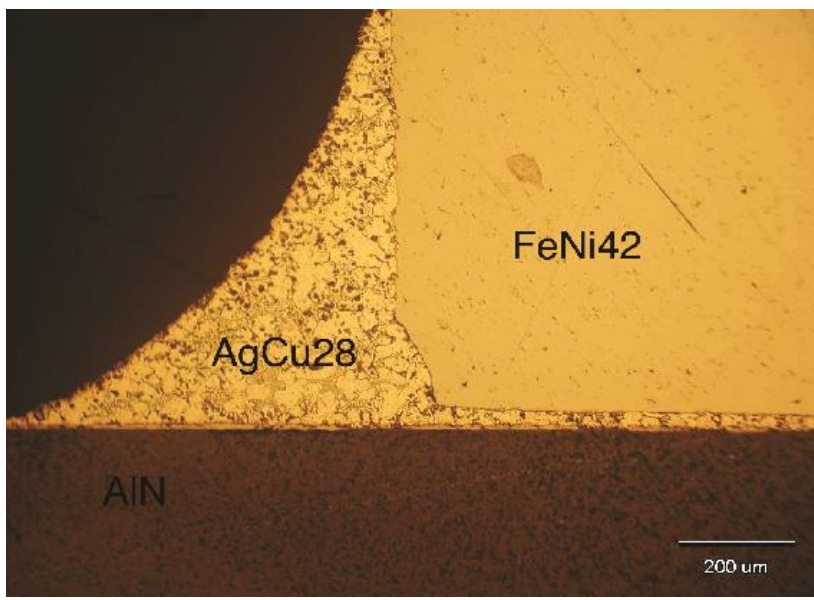

(b)

Fig. 13. a) Microstructure of the AlN-AgCu28-FeNi42 soldered joint with metallization Ti coating (additionally coated with nickel); b) microstructure of the soldered joint AlN substrate; frictionally deposited Ti coating; AgCu28 Feb; FeNi42

\section{Discussion of the results and summary}

The technological processes of metallization of ceramics, especially those that entered the mass production phase due to the high quality of the connections obtained, usually take place at high temperatures in vacuum or advanced protective atmospheres. They are usually time-consuming (up to several dozen hours), and during them the entire volume of material is heated. 
From a thermodynamic point of view, to create a new interface between two free surfaces, activation energy at the energy barrier level is needed, preferably delivered only to the connection area. In conventional methods of ceramic metallization, proven in industrial practice, the energy needed to create the connection is provided indirectly by heating the entire volume of the furnace chamber or indirectly, through an immersion or induction heater. In rare cases, direct heating, e.g. microwave, is used. In these cases, the entire volume is usually heated, not just the zone of the resulting joint, which is associated with excessive energy consumption.

Supplying energy in a mechanical way, as used in this work, by converting kinetic energy into heat in the light of completed research seems to be an effective factor in the ceramic metallization process. A characteristic feature of the metallization method based on mechanical energy supply is the heat release directly at the interface between the connections $[18,24]$. The amount of energy released at the same time can be measured at the minimum level needed to create the connection [25], absolutely incomparable with the amount of energy spent in conventional metallization methods. Another advantageous factor resulting from the very essence of the mechanical (frictional) method of energy supply is the removal of impurities and adsorbed coatings from the metallized surface. This leads to an increase in the free energy of the metallized surface and can be regarded as a specific activation of the surface, lowering the energy barrier of welding. The heat emitted on the metallized surface stimulates diffusion processes and facilitates plasticizing of the metal. Temperature gradients directed perpendicular to the metallized surface are a diffusion intensifying factor [26].

From the tests carried out, the possibility of performing a useful and economically attractive metallization titanium coating on the AlN surface is outlined. Provided that argon gas protection is used, it is possible to limit the phenomenon of titanium oxidation despite heating it to a relatively high temperature. The obtained coatings are continuous and relatively homogeneous, well bonded to the substrate, with a stereometric structure and phase structure favoring wettability with classic solders, e.g. AgCu28 in the context of using a metallization coating as a transition layer for soldering with metals.

The research results presented in the work confirm that the friction method can effectively metallize the surface of AlN ceramics.

The proposed friction metallization method enables the production of full-value coatings on the surface of advanced ceramics and complements the range of already used methods of technological ceramic metallization. The tests and results obtained prove that the conversion of kinetic friction energy into thermal energy is an effective solid state bonding agent used for metallization of ceramics, despite the fact that the parameters characterizing the process (such as temperature and time) do not reach the values commonly expected during conventional metallization ceramics. Significant cyclic stresses in the surface layer and a temperature gradient significantly increase the chemical potential gradient stimulating solid state bonding.

Metallization of AlN ceramics with the use of kinetic friction energy can become an alternative to currently used costly, complex and long-lasting methods of ceramic metallization. Friction metallization processes can be used to modify the surface properties of ceramic elements, which can be used as an interlayer in later stages, e.g. for bonding by conventional methods with metal elements.

Funding: This research received no external funding

Conflicts of Interest: The author declares no conflict of interest.

\section{Resources}

[1] Nascimento R.M. do., Martinelli A.E., Buschinelli A.J.A., Review Article: recent advances in metal-ceramic brazing. Cerâmica, 2003, Vol. 49(312), 178-98. https://doi.org/10.1590/s0366-69132003000400002

[2] Pietrzak K., Kaliński D., Chmielewski M., Chmielewski T., Włosiński W., Choregiewicz K., Processing of intermetallics with $\mathrm{Al} 2 \mathrm{O} 3$ or steel joints obtained by friction welding technique.In: Proceedings of the 12 th Conference of the European Ceramic Society - ECerS XII Stockholm, Sweden - 2011 Internet, 2011, 1-4.

[3] Skowrońska B., Chmielewski T., Sałaciński T., Swiercz R., AlN ceramics metallization with titanium by means dgun spraying method.In: METAL 2019 - 28th International Conference on Metallurgy and Materials, Conference Proceedings Internet, 2019, 1151-7.

[4] Włosiński W., Chmielewski T., Grabowska A., Góra A., Warunki spajania tarciowego i struktura złączy Al2O3Al i Al2O3-Cu. Przeglad Spawalnictwa Internet, 2003, Vol. 75(12), 1-5.

[5] Dai X., Cao J., Chen Z., Song X., Feng J., Brazing SiC ceramic using novel B4C reinforced Ag-Cu-Ti composite filler. Ceramics International, 2016, Vol. 42(5), 6319-28. https://doi.org/10.1016/j.ceramint.2016.01.021

[6] Sekulić D.P., Advances in brazing: Science, technology and applications.Advances in Brazing: Science, Technology and Applications. 2013. https://doi.org/10.1533/9780857096500 
[7] Mirski Z., Brazing a graphite composite to molybdenum alloy TZM using active copper-based filler metals with chromium additive. Archives of Metallurgy and Materials, 2011, Vol. 56(3), 829-37. https://doi.org/10.2478/v10172011-0092-y

[8] Zhu S., Włosiński W., Joining of AlN ceramic to metals using sputtered Al or Ti film. Journal of Materials Processing Technology, 2001, Vol. 109(3), 277-82. https://doi.org/10.1016/S0924-0136(00)00814-1

[9] Chmielewski T., Hudycz M., Krajewski A., Salaciński T., Skowrońska B., Świercz R., Structure investigation of titanium metallization coating deposited onto aln ceramics substrate by means of friction surfacing process. Coatings, 2019, Vol. 9(12). https://doi.org/10.3390/coatings9120845

[10] Chmielewski T., Metallization of Aln Ceramic with Ti Using Detonation Spraying Process - Thermodynamic Approach. Journal of Manufacturing Technologies Internet, 2018, Vol. 43(1), 11-9.

[11] Li J., Wei P., Qiliang H., Chen J., Zhang Z., Mechanism of titanium deposition on AlN surface by molten salt reaction. Materials Letters, 2003, Vol. 57(8), 1369-73. https://doi.org/10.1016/S0167-577X(02)00989-8

[12] Chmielewski T., Golański D., Włosiński W., Zimmerman J., Utilizing the energy of kinetic friction for the metallization of ceramics. Bulletin of the Polish Academy of Sciences: Technical Sciences, 2015, Vol. 63(1), $201-7$. https://doi.org/10.1515/bpasts-2015-0023

[13] Włosiński W.K., The joining of advanced materials.Oficyna Wydawnicza Politechniki Warszawskiej, 1999.

[14] Piekoszewski J., Krajewski A., Prokert F., Senkara J., Stanisławski J., Waliś L., et al., Brazing of alumina ceramics modified by pulsed plasma beams combined with arc PVD treatment. Vacuum, 2003, Vol. 70(2-3), 307-12. https://doi.org/10.1016/S0042-207X(02)00660-7

[15] Zdunek K., Concept, techniques, deposition mechanism of impulse plasma deposition - A short review. Surface and Coatings Technology, 2007, Vol. 201(9-11), 4813-6. https://doi.org/10.1016/j.surfcoat.2006.07.024

[16] Wolf R., Sparavigna A.C., Role of Plasma Surface Treatments on Wetting and Adhesion. Engineering, 2010, Vol. 02(06), 397-402. https://doi.org/10.4236/eng.2010.26052

[17] Hashiguchi M., Sakaguchi I., Sakamoto N., Yurimoto H., Hishita S., Ohashi N., Ion implantation and diffusion of zinc in dense SnO2 ceramics. Journal of the Ceramic Society of Japan, 2013, Vol. 121, 1004-7. https://doi.org/10.2109/jcersj2.121.1004

[18] Hudycz M., Friction metallization of AlN ceramics with titanium. Warsaw University of Technology, 2019.

[19] Sałaciński T., Winiarski M., Przesmycki A., Świercz R., Chmielewski T., Applying titanium coatings on ceramic surfaces by rotating brushes.In: METAL 2018 - 27th International Conference on Metallurgy and Materials, Conference Proceedings Internet, 2018. p. 1235-40.

[20] Zimmerman J., Wlosinski W., Lindemann Z.R., Thermo-mechanical and diffusion modelling in the process of ceramic-metal friction welding. Journal of Materials Processing Technology, 2009, Vol. 209(4), 1644-53. https://doi.org/10.1016/j.jmatprotec.2008.04.012

[21] Włosiński W., Chmielewski T., Zimmerman J., Technology for bonding elastic materials (ceramics of Al2O3, AlN, $\mathrm{SiC}$, Si3N4, TiN types) with plastic materials (steels, intermatallics, composites) using friction.Selected research findings of an innovative nature, Polish Academy of Science. 2007.

[22] Włosiński W., Chmielewski T., Torzewski A., Joining of alumina (A12O3) with metals by the friction welding method.In: Proc 111st Int Conf on Advanced in Production Engineering, Warsaw Internet, 2004. p. 9-19.

[23] Chmielewski T., Application of kinetic friction energy and detonation wave for metallization of ceramics. Warsaw, Publishing House of Warsaw University of Technology, 2012. 3-157 p.

[24] Skowrońska B., Chmielewski T., Pachla W., Kulczyk M., Skiba J., Presz W., Friction weldability of UFG 316L stainless steel. Archives of Metallurgy and Materials, 2019, Vol. 64(3), 1051-8. https://doi.org/10.24425/amm.2019.129494

[25] Lakshminarayanan A.K., Balasubramanian V., Process parameters optimization for friction stir welding of RDE40 aluminium alloy using Taguchi technique. Transactions of Nonferrous Metals Society of China (English Edition), 2008, Vol. 18(3), 548-54. https://doi.org/10.1016/S1003-6326(08)60096-5

[26] Hudycz M., Chmielewski T., Golański D., Analysis of Distribution of Temperature and Stresses During the Friction Metallisation of AIN Ceramics with Titanium. Biuletyn Instytutu Spawalnictwa, 2016, Vol. 60(5), 63-7. https://doi.org/10.17729/ebis.2016.5/9

(C) 2020 by the authors. Submitted for possible open access publication under the terms and conditions of the Creative Commons Attribution (CC BY) license (http://creativecommons.org/licenses/by/4.0/). 